University of Nebraska - Lincoln

DigitalCommons@University of Nebraska - Lincoln

USDA Wildlife Services - Staff Publications

U.S. Department of Agriculture: Animal and Plant Health Inspection Service

2019

\title{
Movement responses inform effectiveness and consequences of baiting wild pigs for population control
}

\author{
Nathan P. Snow \\ USDA APHIS Wildlife Services NWRC, Nathan.P.Snow@usda.gov \\ Kurt C. VerCauteren \\ USDA APHIS Wildlife Services NWRC, kurt.c.vercauteren@usda.gov
}

Follow this and additional works at: https://digitalcommons.unl.edu/icwdm_usdanwrc

Part of the Natural Resources and Conservation Commons, Natural Resources Management and Policy Commons, Other Environmental Sciences Commons, Other Veterinary Medicine Commons, Population Biology Commons, Terrestrial and Aquatic Ecology Commons, Veterinary Infectious Diseases Commons, Veterinary Microbiology and Immunobiology Commons, Veterinary Preventive Medicine, Epidemiology, and Public Health Commons, and the Zoology Commons

Snow, Nathan P. and VerCauteren, Kurt C., "Movement responses inform effectiveness and consequences of baiting wild pigs for population control" (2019). USDA Wildlife Services - Staff Publications. 2256. https://digitalcommons.unl.edu/icwdm_usdanwrc/2256

This Article is brought to you for free and open access by the U.S. Department of Agriculture: Animal and Plant Health Inspection Service at DigitalCommons@University of Nebraska - Lincoln. It has been accepted for inclusion in USDA Wildlife Services - Staff Publications by an authorized administrator of DigitalCommons@University of Nebraska - Lincoln. 


\title{
Movement responses inform effectiveness and consequences of baiting wild pigs for population control
}

\author{
Nathan P. Snow ", Kurt C. VerCauteren \\ USDA/APHIS/ Wildlife Services, National Wildlife Research Center, 4101 LaPorte Ave., Fort Collins, CO, 80521, USA
}

\section{A R T I C L E I N F O}

\section{Keywords:}

Behavior

Feral swine

Integrated pest management

Sus scrofa

Trapping

Wild boar

Wildlife damage management

\begin{abstract}
A B S T R A C T
Wild pigs (Sus scrofa) damage agricultural and natural resources throughout their nearly global distribution. Subsequently, population control activities (e.g., trapping, shooting, or toxic baiting) frequently involve the deployment of bait to attract wild pigs. A better understanding of how wild pigs respond to bait sites can help maximize efficiency of baiting programs and identify any potential pitfalls. We examined the movement behaviors of 68 wild pigs during three stages of intensive baiting programs (i.e., 15 days each: prior, during, and post baiting) spread across two distinct study areas in southern and northern Texas, USA. We found that bait sites needed to be within $1 \mathrm{~km}$ of where females were located $(1.25 \mathrm{~km}$ for males) to achieve $\geq 0.50$ daily visitation rate. Deployment of bait increased movement distances and erratic movements for both sexes, but did not influence their foraging search area. Home range sizes increased and shifted during baiting, especially for wild pigs on the periphery of the baiting area. After baiting ceased, wild pigs moved away from bait sites and began using new space (i.e., less overlap with previously used home ranges), suggesting that baiting could facilitate the spread of wild pigs. We recommend that baiting programs should be coordinated to reduce the number of wild pigs left on the landscape following baiting. Bait sites should be spaced every $1-2 \mathrm{~km}$, and should be actively relocated if visitation by wild pigs is not consistent. Uncoordinated and passive baiting for recreational hunting and trapping likely exacerbates the negative consequences of baiting identified in this study, such as expanding the space-use and facilitating the spread of wild pigs.
\end{abstract}

\section{Introduction}

Wild pigs (Sus scrofa), also termed feral hogs, feral pigs, feral swine, invasive wild pigs, or wild boar (Keiter et al., 2016), are a widely distributed species throughout all continents except Antarctica (Barrios-Garcia and Ballari, 2012). In North America in particular, wild pigs are rapidly expanding in distributed range (Brook and van Beest, 2014; Corn and Jordan, 2017; Snow et al., 2017a). Wild pigs consume agricultural plants (Schley and Roper, 2003; Ditchkoff and Mayer, 2009), costing an estimated annual \$USD 1.5 billion in crop damages and control costs in the USA (Pimentel 2007). Populations of wild pigs often are intensively controlled and hunted (Steen, 2006; Gamelon et al., 2012; Ditchkoff et al., 2017; Davis et al., 2018; Rosa et al., 2018) to curtail their extensive damage to agriculture and property, or reduce the risk of disease spread to humans and livestock (Mayer and Brisbin, 2009; Barrios-Garcia and Ballari, 2012; Bevins et al., 2014). In addition, hunting or trapping of wild pigs is also popular throughout most of their distributed range for food or sport (Henry, 1966; Ditchkoff et al., 2017;

\section{Rosa et al., 2018).}

Baiting of wild animals has positive and negative attributes for wildlife management and control. Baiting can increase efficacy of population control activities by attracting the pest species across broad landscapes (Lavelle et al., 2017). However despite this increased removal, baiting also generates unwanted conditions such as concentrating animals, increasing contact and spread of diseases, increasing fecundity, habituating wild animals to humans, and more (Dunkley and Cattet, 2003; The Wildlife Society, 2007; Sorensen et al., 2014). Specifically for wild pigs, baiting programs that do not target removal of all animals within an area result in overall population increases (Ditchkoff et al., 2017), and only short-lived population decreases owing to rapid immigration from surrounding areas (Hone and Pedersen, 1980; Delgado-Acevedo et al., 2013).

Baiting is one of the most commonly used methods for applying control methods for wild pigs, or monitoring populations of wild pigs (Mayer and Brisbin, 2009; Engeman et al., 2013; Bengsen et al., 2014; Lavelle et al., 2017). Typically, baits stimulate both smell and taste for

\footnotetext{
* Corresponding author.

E-mail address: Nathan.P.Snow@usda.gov (N.P. Snow).
} 
wild pigs, and provide sustenance (Lavelle et al., 2017). Prolonged applications of bait may be needed to overcome neophobic behaviors of some wild pigs (Muir and McEwen, 2007; Campbell et al., 2010; Lavelle et al., 2018b; Snow et al., 2018). As such, baiting programs usually rely on consistent and repeated visitations to bait sites before initiating population control activities (Campbell et al., 2006; Williams et al., 2011a; Snow et al., 2016; Lavelle et al. 2018a, 2018b). Application of bait may also be attempted to attract wild pigs from adjacent lands that cannot be easily accessed, to extend the reach of population control. Wild pigs reportedly respond to bait sites from radii of $1.5-1.7 \mathrm{~km}$ around the sites (Davis et al., 2017; Lavelle et al., 2018b; Snow et al., 2018). However, Lavelle et al. (2018b) also demonstrated that the longer it takes for wild pigs to initially find bait sites, the lower their probability of repeated visitation to bait sites. Therefore for those wild pigs on the periphery of attraction that may not find bait sites quickly, it remains unclear how susceptible they are to population control, and if they alter their movement behaviors to become more susceptible.

Additionally, not all wild pigs are typically removed from the landscape during baiting programs for population control. For example, trapping has been reported to remove only $62-83 \%$ of wild pigs that encountered traps (Choquenot et al., 1993; Saunders et al., 1993; Vernes et al., 2001; Williams et al., 2011b). Toxic baiting programs have reported higher potential for population control (e.g., 91-98\%; Poché et al., 2018; Snow et al., 2018), but took >6 weeks to achieve in one study (Poché et al., 2018). Given that some wild pigs are not removed or not removed quickly, it is unclear how baiting programs impact the space-use and geographic distribution for the remaining population on the landscape. Understanding how the remaining population responds after baiting can elucidate potential consequences for not removing entire populations, such as shifts in space-use.

To better understand the area that baiting programs target wild pigs, and how baiting programs influence movement responses of wild pigs, we conducted extensive baiting programs in two distinct study locations and monitored the responses of GPS collared wild pigs. Our objectives were; 1 ) to evaluate the distances that wild pigs were drawn to bait sites and thus susceptible to population control, and 2) to evaluate whether space-use, movement distances, and foraging patterns of wild pigs are influenced by a baiting program. Our goal was to provide guidance for maximizing exposure of wild pigs for population control and examine for any potential consequences of baiting programs in the movements and space-use of wild pigs that are not removed by population control activities.

\section{Methods}

\subsection{Study area}

The study took place in two locations, south-central Texas, USA during June-August 2016 and north-central Texas, USA during January-March 2018 (Fig. 1). The south-central location was a military property (Camp Bullis operated by Joint Base San Antonio) encompassing $112.9 \mathrm{~km}^{2}$ located in Bexar County. The property lies on the Edwards Plateau and Blackland Prairie ecoregions of south-central Texas (Bailey, 1980, 1998). Vegetation communities are dominated by a mosaic of cedar (Juniperus ashei) and oak (Quercus spp.) woodlands intermixed with grasslands on rocky soils and limestone outcrops (Hudler, 2000; Wills, 2006). Average temperatures during the study ranged from 22 to $30.7{ }^{\circ} \mathrm{C}$ and average precipitation ranged from 0 to $8.13 \mathrm{~mm}$ per day (National Climatic Data Center). The north-central location was private rangeland encompassing $52 \mathrm{~km}^{2}$ in Wilbarger County. The property lies within the Southwest Plateau and Plains Dry Steppe and Shrub ecoregion of North America (Bailey, 1980, 1998). Vegetation communities are dominated by a mosaic of wheat (Triticum spp.) croplands, grasslands, and mesquite (Prosopis spp.) and oak woodlands (Asner et al., 2003) on outwash, red-bed, and alluvium soils (Koos et al., 1962).

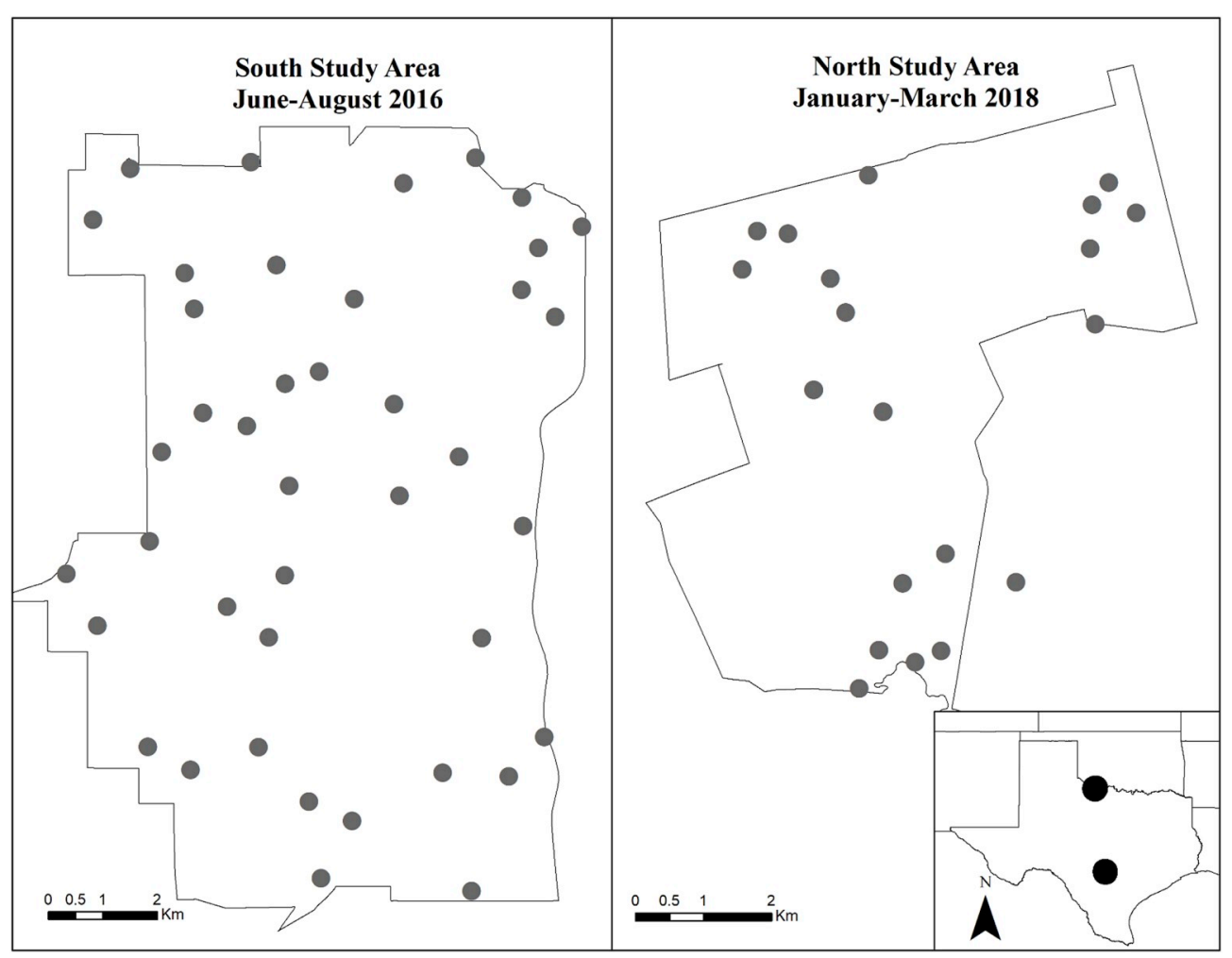

Fig. 1. Study areas in south-central Texas, USA during June-August 2016 and north-central Texas, USA during January-March 2018. Gray dots represent final bait sites for wild pigs. 


\section{Methods}

\subsection{Capturing and collaring wild pigs}

We captured wild pigs using baited corral and box traps. Trapping in the southern study area was conducted during 27 Jan - 06 March 2016; 4-6 months prior to experimental baiting. Here, we used whole-kernel corn for trapping and experimental baiting, but because of the 4-6 month lag, we do not expect that trapping conditioned the wild pigs to whole-kernel corn during experimental baiting. Trapping in the northern study areas was conducted during 12-17 January 2018; 2 weeks prior to experimental baiting. Here, we used a commercial hog feed (Producer's Pride ${ }^{\circledR}$ Hog Feed, Tractor Supply Company, Brentwood, TN, USA) to bait wild pigs for trapping, to avoid conditioning the animals to whole-kernel corn used for experimental baiting. All baiting for trapping purposes was conducted without bait stations, to avoid conditioning the wild pigs to bait stations prior to experimental baiting.

Once trapped, we chemically immobilized adult wild pigs ( $>36 \mathrm{~kg}$ ) for attaching Global Positioning System (GPS) satellite-transmitting collars (VERTEX PLUS-2 Collar, VECTRONIC Aerospace GmbH, Berlin, Germany) and uniquely identifiable ear tags (Y-Tex Cattle Tags, Y-Tex ${ }^{\circledR}$ Corporation, Cody, Wyoming, USA, and 7X Ear Tags, Premier1Supplies, Washington, Iowa, USA). All juvenile and neonate wild pigs were released without chemical immobilization. We immobilized adult wild pigs in traps using a mixture of $3.3 \mathrm{mg} / \mathrm{kg}$ Telazol ${ }^{\mathbb{B}}(200 \mathrm{mg} / \mathrm{ml})$ and $1.5 \mathrm{mg} / \mathrm{kg}$ xylazine $(100 \mathrm{mg} / \mathrm{ml}$; Wildlife Pharmaceuticals, Inc., Windsor, Colorado, USA; Sweitzer et al., 1997) or a $0.17 \mathrm{ml} / \mathrm{kg}$ dose from a $1: 1: 1$ solution of medetomidine $(10 \mathrm{mg} / \mathrm{ml})$, butorphenol $(50 \mathrm{mg} / \mathrm{ml})$, and midazolam $(50 \mathrm{mg} / \mathrm{ml}$; Wildlife Pharmaceuticals, Inc.,) via intramuscular injection. We programmed the collars to collect and store locations every $15 \mathrm{~min}$. Locational error for the collars was assessed to be $\leq \pm 5.0 \mathrm{~m}(\mathrm{SE}=0.16)$ using 2,840 fixes truthed with a Trimble GEOXH 2008 (Trimble Navigation, Sunnyvale, California). All procedures were approved by the Institutional Animal Care and Use Committees from Texas A\&M University-Kingsville (2015-08-20) and the United States Department of Agriculture/Animal Plant and Health Inspection Service/Wildlife Services (USDA/APHIS/WS), National Wildlife Research Center (QA-2632, and QA-2612).

Overall, we trapped and fitted GPS collars onto 75 wild pigs during 43 trapping events. The number of wild pigs fitted with collars ranged from 1 to 8 per capture event (averaging 1.7 per trapping event). Seven of the 75 wild pigs either slipped collars or were killed prior to initiation of the study. Therefore, the sample consisted of 68 wild pigs ( 36 females and 32 males), including 32 during 2016 and 36 during 2018. Among the 68 wild pigs, we classified them into unique groups to account for pseudo-replication among grouped individuals. We classified any two or more wild pigs with home ranges that overlapped by $\geq 80 \%$ (see home range methodology below) prior to experimental baiting as being grouped. In total, we observed 55 unique groups of wild pigs from the sample of 68 collared animals.

\subsection{Baiting wild pigs}

We divided the study duration into three study periods, including pre-baiting, baiting, and post-baiting. The pre-baiting period was considered as a 15-day period prior to establishing any bait sites and deploying bait. Deployment of bait occurred for 20-24 days in each study site, but we only considered the final 15 days of bait deployment as the baiting period to ensure consistent durations among all periods. The post-baiting period was defined as a 10-15-day period after bait sites were removed. The period was 10 days long for 33 wild pigs whose collars remotely dropped off after only 10 days into the period to ensure retrieval of collars with low battery life. All other pigs had a 15-day postbating period. We separated all periods using buffers of six days each. These buffers were excluded from analysis to maximize independence of wild pig behaviors amongst the study periods. Some animals died during the study, therefore we had 68,68 , and 54 wild pigs collared during the pre-baiting, baiting, and post-baiting periods, respectively.

We initially established 61 bait sites in June 2016 in the southern study area, and 43 bait sites in January 2018 in the northern study area. We selected sites by overlaying the study areas with $0.75 \mathrm{~km}^{2}$ grids, and placing $0-3$ bait sites per grid cell in areas that had fresh sign of pigs. (i.e, rooting, wallowing, bedding, etc.). After 1-6 days of baiting at these sites, we narrowed the number of bait sites to 41 in the south and 20 in the north based on which sites had the most visitation by wild pigs with GPS collars (Fig. 1). We narrowed the bait sites so that each grid cell contained $\leq 1$ bait site, for a maximum baiting density of 1 bait site per $0.75 \mathrm{~km}^{2}$. Specifically, the sites that we excluded either had no visitation by wild pigs, or infrequent visitation by only a few wild pigs (e.g., $\leq 3$ ) usually without GPS collars. We assumed that narrowing the bait sites did not have substantial influence on movements of the GPS collared animals because those animals were mostly not using the excluded sites.

We deployed bait consistent with the baiting strategy developed for conditioning wild pigs for eventual deployment of toxic bait to meet objectives of a larger research objective (Lavelle et al., 2018b; Snow et al., 2018). This strategy was designed to maximize consistent and repeated visitation by wild pigs to bait sites while accustoming them to feeding from a wild pig-specific bait station (Snow et al., 2017b; Lavelle et al., 2018a). The bait station was comprised of back-to-back troughs with lids that were secured with $\sim 13 \mathrm{~kg}$ of magnetic pressure. Specifically, we established bait sites using $\sim 11 \mathrm{~kg}$ of whole-kernel corn placed on the ground. Once wild pigs were observed visiting a site consistently or until 6 days, we introduced the bait station and started putting bait inside. After day 6, we started transitioning from whole-kernel corn to placebo HOGGONE ${ }^{\mathbb{B}}$ (Animal Control Technologies Australia PTY Ltd, Victoria, AU; Snow et al., 2016) by slowly increasing the amount of placebo HOGGONE until a total of $20 \mathrm{~kg}$ of placebo and $1 \mathrm{~kg}$ of corn were offered, following Snow et al. (2018). Placebo HOGGONE ${ }^{\circledR}$ has been demonstrated to be equally attractive to wild pigs as whole-kernel corn (Snow et al., 2016). All bait sites were refreshed daily.

\subsection{Visits to bait sites by wild pigs}

We sought to determine how placement of the bait sites relative to where wild pigs lived influenced visitation to the bait sites for both males and females. Specifically, we calculated the average distance each wild pig was located away from the nearest bait site during the prebaiting period. Then, we determined whether each wild pig visited a bait site during the baiting period using the rule that any GPS location $\leq 25 \mathrm{~m}$ from a bait sites constituted a wild pig visiting that bait site. Finally, we examined how many days each of the wild pigs visited the bait sites during the 15-day baiting period as an indicator of consistency in visitation. We used the daily visitation rate to make inference to the reliability of exposing that animal to potential population control activities (e.g., setting a trap, deploying a toxic bait, or shooting) during any given night.

\subsection{Movement Behaviors of Wild Pigs Relative to bait sites}

For each study period, we calculated the hourly movement distances of wild pigs using the adehabitat package (Calenge, 2006) in program $\mathrm{R}$ (v3.4.1; R Foundation for Statistical Computing, Vienna, Austria). We averaged the hourly distances moved by each wild pig at night, where night was considered as sunset to sunrise (https://www.timeanddate. $\mathrm{com} / \mathrm{sun} / \mathrm{usa} /$ ) for each respective study area and season. We used nightly distances because movement activity by wild pigs has been reported as being primarily nocturnal (Keuling et al., 2008). We also calculated a metric of variation (SE) in nightly movement distances for each wild pig to examine increases or decreases in erratic movements through time. Finally, we used AcrGIS (v10.5.1, Environmental Systems Research Institute, Redlands, CA, USA) to calculate the average distance 
that wild pigs were located away from the nearest bait site during each bating period.

We estimated the $95 \%$ utilization distribution (i.e., home ranges) of wild pigs during each of the study periods. Specifically, we used the adehabitatHR package (Calenge, 2006) in Program R to employ a movement-based kernel density estimator (MKDE; Benhamou and Cornelis, 2010; Benhamou, 2011). We parameterized the MKDE analysis with an upper time limit of $1 \mathrm{~h}$ between fixes and considered fixes $\leq 12 \mathrm{~m}$ apart (i.e., $\geq 2$ times the GPS error) to be inactive. We calculated centroids of home ranges using the sp package in program $\mathrm{R}$ (Pebesma and Bivand, 2005). We considered the pre-baiting home range as the baseline home range, and calculated distances from centroids of these home ranges to the nearest bait sites. Finally, relative to the baseline home ranges for each wild pig, we calculated the changes in home range sizes and shifts in home ranges (i.e., proportion of home range overlap) during the baiting and post-baiting periods, respectively.

We performed first-passage time (FPT) analysis for each wild pig to examine their spatial scale of foraging activity (i.e., foraging search area) during each of the study periods. Specifically, we examined the time it took for wild pigs to move beyond a given radius (Fauchald and Tveraa, 2003), where high passage times are indicative of intensive foraging movements (e.g., short, deliberate movements) and low passage times are associated with non-foraging movements (e.g., fast, direct movement). We excluded all daytime locations and any nighttime locations where wild pigs moved $\leq 10 \mathrm{~m}$ in $15 \mathrm{~min}$, to remove times when wild pigs were likely resting. We calculated the FPT at each wild pig location using radii of $5-500 \mathrm{~m}$ in $5 \mathrm{~m}$ increments. For each pig, we calculated the maximum mean variance of the log-transformed FPT to represent the spatial scale at which wild pigs concentrated their search effort (Fauchald and Tveraa, 2003) during each of the baiting periods. We considered these measures as the foraging search area for each wild pig.

\subsection{Data analysis}

Visits to Bait Sites by Wild Pigs - We used a binomial generalized mixed model with a logit link in program $\mathrm{R}$ to examine how the distance wild pigs lived from bait sites influenced the probability that male and female wild pigs visited a bait site. Then, we used a Poisson generalized mixed model with a log link to examine how that same distance influenced the number of days that male and female wild pigs visited a bait site during the 15-day bating period. For both models, we treated the study site (north or south) as a random grouping variable. We constructed predictive plots and 95\% confidence intervals (CIs) around the predictions to examine the predicted relationships. For predictive inferences from the latter model, we divided the predicted number of days wild pigs visited a bait site by the total 15 days, to depict the predicted daily rate of visitation.

Movement Behaviors of Wild Pigs Relative to Bait sites - We conducted separate model selection procedures for each of the 7 response variables (average nightly movement distance, variation in average nightly movement distance, average distance to nearest bait site, home range size, change in home range size, shift in home range, and foraging search area) using the MuMIN package (Barton, 2009) in program R. For each procedure, we used linear mixed models in Package lme4 (Bates et al., 2014) to examine all combinations of models stemming from the global model of: response variable $\sim$ baiting period + nearest bait site + sex, with 2 exceptions. First, we excluded the covariate, nearest bait site, for the models examining the response variable of average distance to nearest bait site. Second, we used a compound Poisson linear mixed model using the cplm package (Zhang, 2013) for the analysis of foraging search area, because the data were best described by a tweedie distribution. For all models, we considered study site as a random grouping variable. We also attempted to use the 55 group IDs as random grouping variables but experienced model convergence issues indicating over-specification of the models, and therefore we simplified the model by excluding group ID.

For each of the model selection procedures, we used the minimum corrected Akaike Information Criterion (AICc) to rank the models (Burnham and Anderson, 2002; Anderson, 2008). Plausible models were considered as any model $<2.0$ AICc of the top-ranked model. We averaged all plausible models to make inferences from the regression coefficients included in the top-ranked models using the shrinkage technique (Burnham and Anderson, 2002; Anderson, 2008) with the AICcmodavg package in Program R (Mazerolle, 2017). For all models, we examined the $95 \%$ CIs for the regression coefficients for overlap of zero to ascertain which covariates had clear effects on the response variables (Burnham and Anderson, 2002). Finally, we used the model averaged models to construct predictive plots and 95\% CIs around the predictions to examine the predicted relationships. Post hoc, we used a linear mixed model to examine if movement distances increased for wild pigs that visited more bait sites during the baiting period.

\section{Results}

\subsection{Visits to bait sites by wild pigs}

The collared wild pigs in this study were located an average of $0.64 \mathrm{~km}$ (range $=0.24-2.41$ ) from bait sites during the pre-bating period. Seven of the 68 wild pigs (10.3\%) with GPS collars were never recorded visiting a bait site, and were located an average of $0.96 \mathrm{~km}$ $(\mathrm{SE}=0.20)$ from the nearest bait site during the pre-bating period. All other wild pigs visited bait sites, and averaged $0.60 \mathrm{~km}(\mathrm{SE}=0.04)$ away. The probability of visiting a bait site decreased the farther that bait sites were located from wild pigs ( $\beta=-1.87 ; 95 \% \mathrm{CI}=-2.89$ to -0.89 ; Fig. 2). On average, the probability of visiting a bait site declined below $50 \%$ for females located $\geq 2 \mathrm{~km}$ away from the nearest bait site, and for males located $\geq 2.5 \mathrm{~km}$ away. Overall, males had a higher probability of visiting bait sites than females $(\beta=1.13 ; 95 \%$ $\mathrm{CI}=0.12-2.29)$. Females visited an average of $1.9(\mathrm{SE}=0.13)$ bait sites whereas males visited $2.5(\mathrm{SE}=0.20)$ during the baiting period.

The daily rate of visitation to bait sites also declined the farther that bait sites were placed from were wild pigs were located $(\beta=-0.51 ; 95 \%$ $\mathrm{CI}=-0.68$ to -0.36 ). The daily rate of visitation declined below $50 \%$ for females located $\geq 1 \mathrm{~km}$ from bait sites, and $\geq 1.25 \mathrm{~km}$ for males. Males tended to have a higher rate of daily visitation overall $(\beta=0.11$; $95 \% \mathrm{CI}=0.02-0.21$ ).

\subsection{Movement Behaviors of Wild Pigs Relative to bait sites}

We identified only one top model for explaining the nightly movement distance of wild pigs (Table 1 ). This model indicated that movement distances increased during the baiting period $(\beta=21.69 ; 95 \%$ $\mathrm{CI}=8.53-34.85$ ), but this effect diminished by the post-baiting period ( $\beta=-9.68 ; 95 \% \mathrm{CI}=-23.59-4.79$ ). Also, throughout the study males averaged moving $\sim 70 \mathrm{~m}$ farther per hour at night than females ( $\beta=16.84 ; 95 \% \mathrm{CI}=5.85-28.83$ ). We found greater model uncertainty in the analysis of variation in movement distance. All four top models included baiting period, and the model-averaged results indicated that variation increased during the baiting period $(\beta=7.74 ; 95 \%$ $\mathrm{CI}=3.95-11.54$ ), but this effect also diminished by the post bating period ( $\beta=-3.22 ; 95 \% \mathrm{CI}=-7.29-0.84)$. Variation was not influenced by the distance to the nearest bait site $(\beta=-0.002 ; 95 \%$ $\mathrm{CI}=-0.006-0.002)$ or sex $(\beta=1.95 ; 95 \% \mathrm{CI}=-1.27-5.15)$. Model predictions indicated that hourly movement distances increased by $\sim 20 \%$ (i.e., $\sim 70 \mathrm{~m}$ ), and variation in hourly movements increased $\sim 40-50 \%$ during the baiting periods (Fig. 3). The post hoc analysis revealed that movement distances increased as wild pigs visited more bait sites throughout the baiting period ( $\beta=14.60 ; 95 \%$ $\mathrm{CI}=6.77-22.23$ ). On average, their nightly movements increased by $\sim 60 \mathrm{~m}$ per hour for every additional bait site that was visited.

We identified 2 top models for explaining the average distance that 

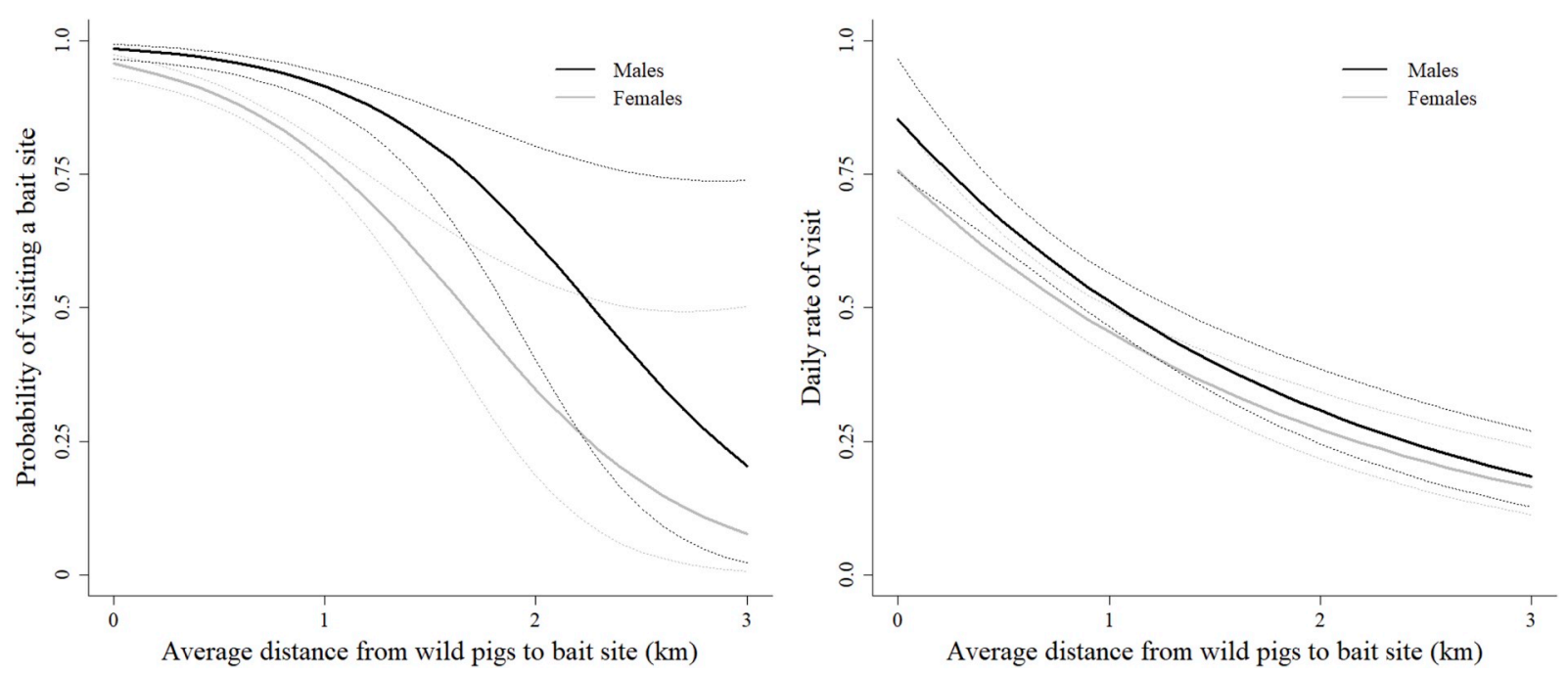

Fig. 2. Model predictions with $95 \%$ CIs for determining the probability that wild pigs visit a bait site, and the daily rate of visitation during baiting programs at two study sites in Texas, USA.

Table 1

Highest-ranked models for describing the hourly movement distance, variation in hourly movement distance, distance to nearest bait site, home range size, change in home range size, shift from previous home range, and foraging search area for wild pigs during baiting programs in southern (summer 2016) and northern (winter 2018) Texas, USA.

\begin{tabular}{|c|c|c|c|c|}
\hline Model $^{\mathrm{a}}$ & $\mathrm{K}^{\mathrm{b}}$ & $\mathrm{AIC}_{\mathrm{c}}^{\mathrm{c}}$ & $\Delta \mathrm{AIC}_{\mathrm{c}}{ }^{\mathrm{d}}$ & $w_{i}^{\mathrm{e}}$ \\
\hline \multicolumn{5}{|l|}{ HOURLY MOVEMENT DISTANCE } \\
\hline$\sim$ Baiting period + Sex & 6 & 1713.7 & 0.00 & 0.72 \\
\hline \multicolumn{5}{|l|}{ VARIATION IN HOURLY MOVEMENT } \\
\hline \multicolumn{5}{|l|}{ DISTANCE } \\
\hline$\sim$ Baiting period & 5 & 1288.8 & 0.00 & 0.36 \\
\hline$\sim$ Baiting period + Sex & 6 & 1289.5 & 0.69 & 0.26 \\
\hline$\sim$ Baiting period + Nearest bait site & 6 & 1289.8 & 0.92 & 0.23 \\
\hline$\sim$ Baiting period + Sex + Nearest bait site & 7 & 1290.6 & 1.74 & 0.15 \\
\hline \multicolumn{5}{|l|}{ DISTANCE LOCATED TO NEAREST BAIT SITE } \\
\hline$\sim$ Baiting period & 5 & 2451.2 & 0.00 & 0.73 \\
\hline$\sim$ Baiting period + Sex & 6 & 2453.1 & 1.96 & 0.27 \\
\hline \multicolumn{5}{|l|}{ HOME RANGE SIZE } \\
\hline$\sim$ Nearest bait site + Sex & 5 & 627.6 & 0.00 & 0.69 \\
\hline$\sim$ Nearest bait site + Sex + Baiting period & 7 & 629.3 & 1.64 & 0.31 \\
\hline \multicolumn{5}{|l|}{ CHANGE IN HOME RANGE SIZE } \\
\hline$\sim$ Nearest bait site + Baiting period & 5 & 450.4 & 0.00 & 0.50 \\
\hline$\sim$ Nearest bait site & 4 & 450.4 & 0.04 & 0.50 \\
\hline \multicolumn{5}{|l|}{ SHIFT FROM BASELINE HOME RANGE } \\
\hline$\sim$ Nearest bait site & 4 & -30.0 & 0.00 & 0.66 \\
\hline$\sim$ Nearest bait site + Baiting period & 5 & -28.8 & 1.30 & 0.34 \\
\hline \multicolumn{5}{|l|}{ FORAGING SEARCH AREA } \\
\hline$\sim$ Nearest bait site & 4 & 1067.3 & 0.00 & 0.64 \\
\hline$\sim()$. & 3 & 1068.5 & 1.11 & 0.36 \\
\hline
\end{tabular}

${ }^{\mathrm{a}}$ Baiting period $=$ pre, during, or post baiting, Sex $=$ male or female, Nearest

bait site $=$ distance from the centroid of home range to the nearest bait site.

b No. of parameters.

c Akaike's Information Criterion adjusted for small sample sizes (Burnham and Anderson, 2002).

${ }^{\mathrm{d}}$ Difference in $\mathrm{AIC}_{\mathrm{c}}$ relative to minimum $\mathrm{AIC}_{\mathrm{c}}$.

e Akaike weight (Burnham and Anderson, 2002).

wild pigs were located away from bait sites (Table 1). Compared to the pre-baiting period, wild pigs were located similar distances from bait sites during the baiting period ( $\beta=6.69 ; 95 \% \mathrm{CI}=-111.66-125.04)$, but moved farther away during the post-baiting period ( $\beta=153.43 ; 95 \%$ $\mathrm{CI}=26.56-280.30)$. We found no differences between sexes $(\beta=23.03$; $95 \% \mathrm{CI}=-77.63-123.69)$. Model predictions indicated that wild pigs on average were $25 \%$ (i.e., $\sim 150 \mathrm{~m}$ ) farther from bait sites during postbaiting (Fig. 3).

The sizes of the home ranges during the pre-baiting period were $2.07 \mathrm{~km}^{2}(\mathrm{SE}=0.26)$ for females and larger for males, $2.69 \mathrm{~km}^{2}$ ( $\mathrm{SE}=0.32 ; \beta=0.73 ; 95 \% \mathrm{CI}=0.27-1.19$ ). The centroids of home ranges ranged from 0.05 to $2.41 \mathrm{~km}$ from the nearest bait sites. We identified two top models for explaining home range size throughout the study (Table 1). Home range sizes were larger for wild pigs that were farther from bait sites ( $\beta=0.0010 ; 95 \% \mathrm{CI}=0.0005-0.0014$ ), and predictions indicated that home ranges were $\sim 1.0 \mathrm{~km}^{2}$ larger for every $1 \mathrm{~km}$ farther away from bait sites (Fig. 4).

We identified two top models for explaining change in home range size, and shifts in home ranges throughout the study, respectively (Table 1). Home ranges became larger for wild pigs located farther from bait sites during the baiting period $(\beta=0.0012 ; 95 \%$ $\mathrm{CI}=0.0004-0.0019$ ) and remained larger during the post-baiting period ( $\beta=-0.55 ; 95 \% \mathrm{CI}=-1.27-0.17)$. Similarly, home ranges shifted more for wild pigs farther from bait sites during the baiting period ( $\beta=-0.0011 ; 95 \% \mathrm{CI}=-0.00020$ to -0.00003$)$, and remained similarly shifted during the post-baiting period $(\beta=0.0012 ; 95 \%$ $\mathrm{CI}=0.0004-0.0019$ ). Model predictions indicated that home ranges contracted for wild pigs with home range centroids $\leq 0.75 \mathrm{~km}$ from bait sites, and expanded by $\sim 1 \mathrm{~km}^{2}$ for every $1 \mathrm{~km}$ farther from bait sites for wild pigs located $>0.75 \mathrm{~km}$ away (Fig. 4). Home range overlap also declined by $\sim 10 \%$ for every $1 \mathrm{~km}$ farther that wild pigs were located from bait sites (i.e., increasing shift in home ranges).

The baseline foraging search area during the pre-baiting period was $13.5 \mathrm{~m}(\mathrm{SE}=1.91)$ for females and was greater $(\beta=0.10 ; 95 \%$ $\mathrm{CI}=0.02-0.17)$ for males, $18.0 \mathrm{~m}(\mathrm{SE}=2.24)$. We identified two top models for explaining foraging search area throughout the study (Table 1). The only covariate included in the top models was distance to the nearest bait site, but did not appear to influence foraging search area $(\beta=0.13 ; 95 \% \mathrm{CI}=-0.02-0.28$; Fig. 5 ).

\section{Discussion}

Our results demonstrate that bait sites periodically attract wild pigs from up to $3 \mathrm{~km}$ away, but only those wild pigs within $1-1.25 \mathrm{~km}$ reliably visit the sites and would be most vulnerable to population control activities. These distances translate to an optimal bait density of 1 bait site per $3.14-4.9 \mathrm{~km}^{2}$, which bisects a wide range of reported bating densities from other evaluations. For example, reported baiting densities ranged from 1 bait site per $6.7 \mathrm{~km}^{2}$ for bait sites in South Carolina and 

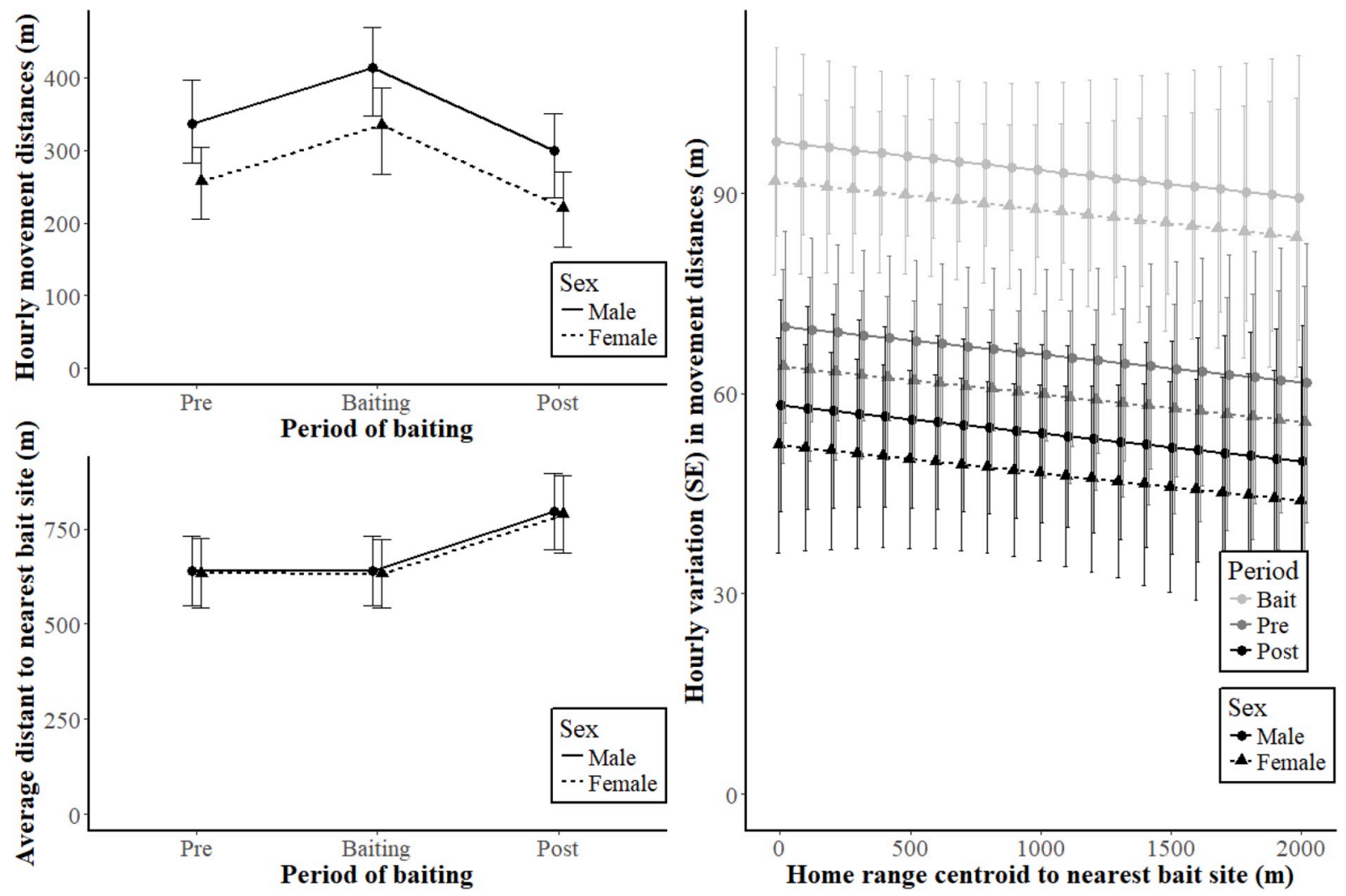

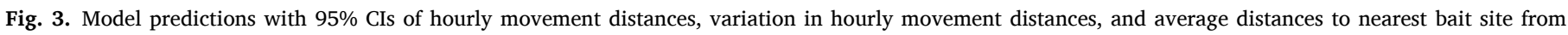
highest-ranked model-averaged models for wild pigs during baiting programs at two study sites in Texas, USA.
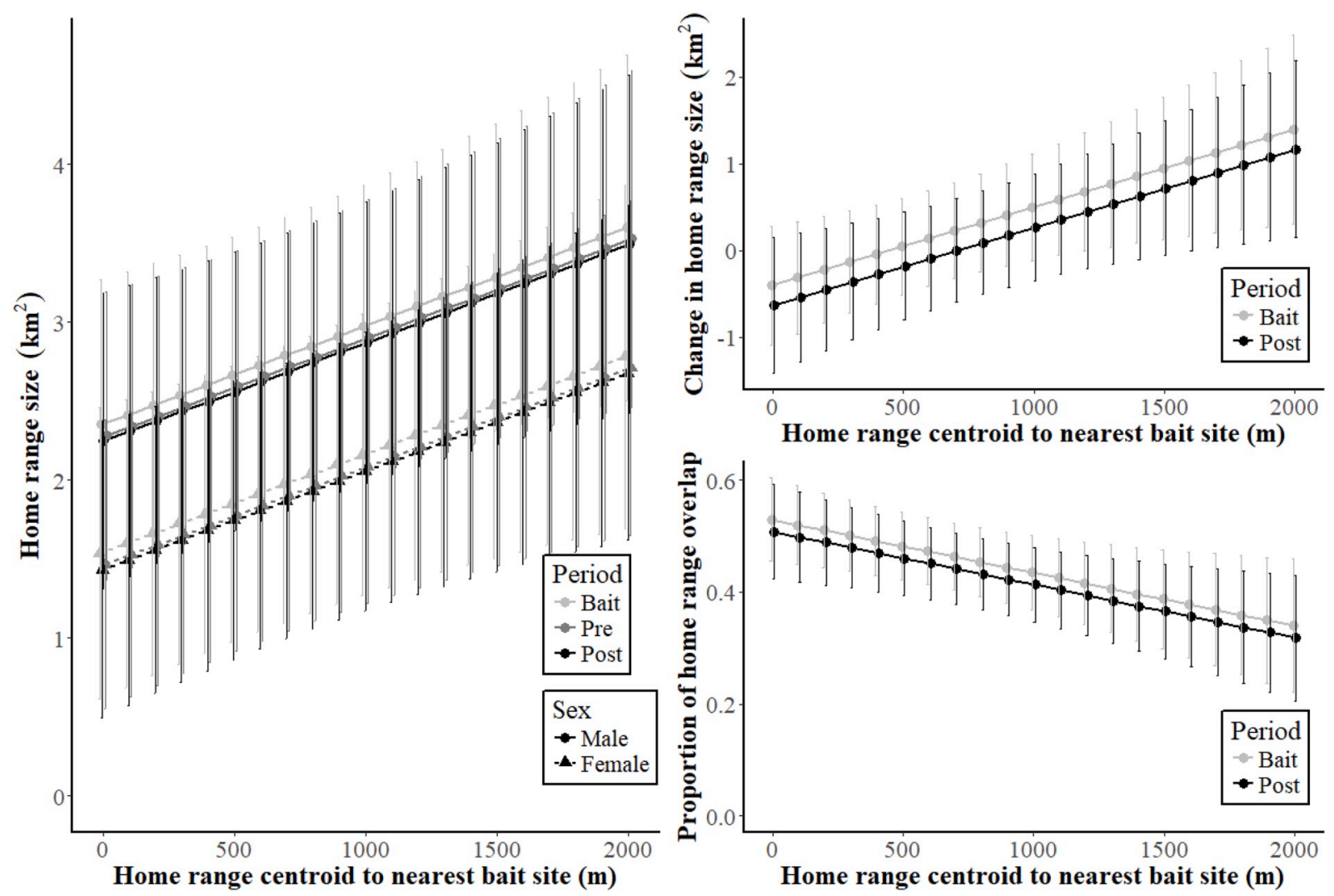

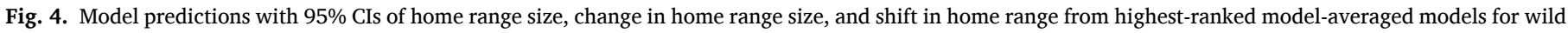
pigs during baiting programs at two study sites in Texas, USA. 


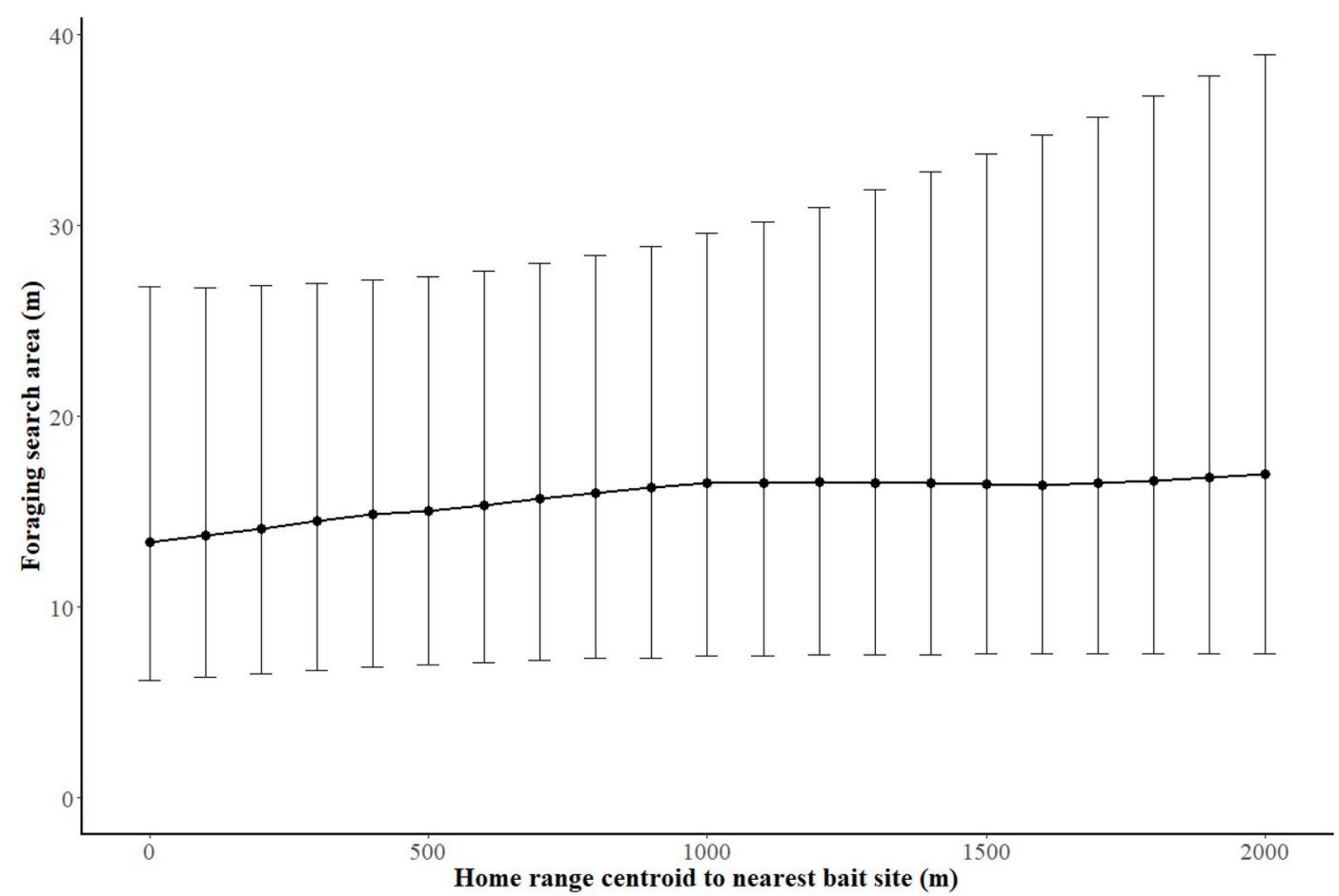

Fig. 5. Model predictions with $95 \%$ CIs of foraging search area from the highest-ranked model-averaged model for wild pigs during baiting programs at two study sites in Texas, USA.

Texas, USA (McRae et al., 2019), to 1 bait site per $0.8-7.1 \mathrm{~km}^{2}$ for bait sites in Texas, USA (Lavelle et al., 2018b; Snow et al., 2018), to 1 bait site per $8.61 \mathrm{~km}^{2}$ for trapping sites in Texas, USA (Davis et al., 2017), to 1 bait site per $0.44-0.67 \mathrm{~km}^{2}$ in Spain (Ballesteros et al., 2011). Despite this variation, this study is the first to focus on a baiting density that optimizes reliable, daily visitation by wild pigs that are ideal for population control activities. Furthermore, Lavelle et al. (2018b) found that if wild pigs did not visit a bait site within the first 6 days that bait was offered, the probability of continued daily visits after the initial visit was substantially lower. We surmise that any late-coming or inconsistently-visiting wild pigs likely live outside the radius of consistent attraction, making them difficult to efficiently expose to population control activities. This suggests that when applying population control activities, maintaining bait sites with infrequent or inconsistent visitation by wild pigs would be less efficient than relocating that bait site to location with more consistent visitations.

To our knowledge, this study is the first to demonstrate that baiting programs have continuing consequences on space-use of wild pigs. We found that baiting programs expanded and shifted home ranges of wild pigs located at least $2.41 \mathrm{~km}$ from bait sites. For pigs on the periphery of the baited area, we observed increases in home range sizes because those wild pigs expanded their space-use to encompass the baited area. Similarly, this expansion resulted in shifts in home ranges as peripheral animals moved into the baiting areas and did not return to the previously used areas. For the wild pigs located farthest from the baited area, predictions indicated that home range sizes increased by $\sim 50 \%$ and overlap between pre- and post-baiting home ranges decreased by $\sim 70 \%$ after baiting ceased. Contrarily, another study did not find these types of changes for wild pigs possibly because only one bait site was used as a baiting treatment (Campbell et al., 2012). We expect that deploying multiple smaller bait sites as done in this study is applicable to current baiting programs, considering Lavelle et al. (2018b) recommended spacing bait sites every $0.75-1.5 \mathrm{~km}$ to efficiently target all wild pigs in an area.

Baiting also increased the distances that wild pigs moved, and increased erratic movements (i.e., higher variation) in this study.
Campbell et al. (2012) similarly showed wild pigs increased movements when bait was deployed. The longer and more erratic movements in this study were related to wild pigs traveling farther distances to visit one or more bait sites. Despite these farther and more erratic movements, we did not detect differences in the foraging search area of wild pigs, suggesting that the presence of supplemental food did not alter their natural searching behaviors. This finding brings forth two potential interpretations. First, the presence of supplemental food in our baiting program did not impact wild pigs enough to alter their natural foraging behavior. This interpretation is supported by the previous finding that supplemental feeding did not alter the behaviors of wild pigs enough to keep them confined to a heavily baited area (Campbell et al., 2012). However, the second interpretation could be that the presence of supplemental food afforded wild pigs more opportunity to pursue other biological requirements not related to food (i.e., territorial marking, wallowing, finding mates) which our analysis could not distinguish. This alternate interpretation is supported by previous findings that supplemental baiting from hunters increased reproduction and population densities of wild pigs (Ditchkoff et al., 2017). More research is needed to determine how the deployment of supplemental food impacts the behavior and population growth of wild pigs, an in particular for those populations that are not being subjected to intensive population control.

Interestingly, wild pigs moved $25 \%$ farther away from bait sites following the end of bait deployment. Reasons behind this behavior are uncertain, but indicative of wild pigs expanding their range after supplemental food is diminished. One likely explanation is that the baiting program caused a high concentration of wild pigs into a confined area (Dunkley and Cattet, 2003; Campbell et al., 2013), and once baiting ceased the animals expanded away to locate sufficient resources. Snow et al. (2017a) calculated that wild pigs are expanding their geographic distribution northward in the USA at a rate of $12.6 \mathrm{~km}$ per year. Any actions, such as baiting, that facilitate range expansion of wild pigs should be employed with caution. Baiting programs on the periphery of the geographic range of wild pigs should ensure that all wild pigs are removed to avoid facilitating spread into previously unoccupied areas.

Some limitations to this study exist. First, we did not undergo 
concentrated efforts to remove wild pigs during our baiting program in 2016, and had minimal removal in 2018, thus most animals remained on the landscape following baiting activities. Previous studies have suggested that wild pigs from surrounding areas will quickly immigrate into areas left vacant by control efforts (Bodenchuk, 2014; Dexter and McLeod, 2015). It is unclear how immigration would further influence movement behaviors of any remaining wild pigs following baiting programs, but could possibly exasperate the negative consequences such as spread of diseases. Second, we monitored wild pigs for 15 days before and after baiting to ensure we captured local effects from baiting. Monitoring for longer durations may provide more insight on how long the effects from baiting programs influenced wild pigs. However, longer durations would also increase the likelihood that other factors could influence the movements of wild pigs (e.g., climatic events, seasonal changes, immigration of surrounding wild pigs, etc.) and confound the study. Finally, we recognize that our design of deploying $>1$ GPS collar on a group of wild pigs can result in a lack of independence among study animals. However, we were surprised to find 55 independent groups among 68 study animals, which supports the hypothesis that groups of wild pigs are loose and highly dynamic (Spencer et al., 2005). Therefore, wild pigs captured in groups may make independent choices and not be pseudoreplicates. Fitting $>1$ GPS collar on groups of wild pigs captured can be efficient for data collection and inferences to the population.

This study helps elucidate the positive and negative consequences of baiting wild pigs, which are similar to those seen with other species such as white-tailed deer (Odocoileus virginianus). Similar to white-tailed deer, targeted baiting programs offer increased efficiency in population control where and when it is needed (Rudolph et al., 2006). However, passive baiting strategies over large areas are akin to supplemental feeding, and are associated with overcrowding and spread of disease (Dunkley and Cattet, 2003; Brown and Cooper, 2006; Campbell et al., 2013; Sorensen et al., 2014). Our results suggest that baiting for intensive population control is most efficient if bait sites are properly spaced (i.e., separated by $1-2 \mathrm{~km}$ ), and if applicators are willing to move their bait sites to locations with consistent wild pig visitation versus waiting for irregularly visiting wild pigs. Passive baiting strategies common with recreational hunters and trappers of wild pigs, which disperse a lot of bait but don't remove a lot of wild pigs (e.g., Ditchkoff et al., 2017), are likely to be exacerbating the invasive spread of wild pigs.

\section{Conclusions}

Based on our findings, we recommend that baiting programs for population control should be coordinated to leave as few wild pigs as possible on the landscape following baiting. Bait sites should be separated by $1-2 \mathrm{~km}$, and should be actively relocated if visitation by wild pigs is not consistent. Baiting along the periphery of inaccessible land can consistently attract pigs from up to $1-1.25 \mathrm{~km}$ away. For attracting wild pigs from farther away, more access to land will be required. Uncoordinated and passive baiting for recreational hunting and trapping likely exacerbates the negative consequences of baiting identified in this study, such as expanding the space-use and facilitating the spread of wild pigs.

\section{Acknowledgements}

The research was supported by the United States Department of Agriculture. We thank S. Carrasco, A. Cooper, J. Davis, B. Friesenhahn, G. Studdard, and R. Tabor for permission and logistical support at the study sites. We thank C. Blass, T. Cochran, C. Ellis, J. Fischer, M. Glow, J. Halseth, A. Killam, C. Kohler, M. Lavelle, A. Maddigan, M. Matticola, H. Sanders, E. VanNatta, P. Ward, C. Wickham, and A. Zarvoi for assisting with trapping, collaring, and baiting wild pigs. We thank S. Ditchkoff and anonymous reviewers for their comments on this manuscript. Mention of commercial products or companies does not represent an endorsement by the US government.

\section{Appendix A. Supplementary data}

Supplementary data to this article can be found online at https://doi. org/10.1016/j.cropro.2019.05.029.

\section{References}

Anderson, D.R., 2008. Model Based Inference in the Life Sciences: a Primer on Evidence. Springer Science \& Business Media, New York, NY, USA.

Asner, G.P., Archer, S., Hughes, R.F., Ansley, R.J., Wessman, C.A., 2003. Net changes in regional woody vegetation cover and carbon storage in Texas drylands, 1937-1999. Glob. Chang. Biol. 9, 316-335.

Bailey, R.G., 1980. Description of the Ecoregions of the United States. US Department of Agriculture, Forest Service.

Bailey, R.G., 1998. Ecoregions, the Ecosystem Geography of the Oceans and Continents, second ed. Springer-Verlag, New York, USA.

Ballesteros, C., Vicente, J., Carrasco-García, R., Mateo, R., de la Fuente, J., Gortázar, C., 2011. Specificity and success of oral-bait delivery to Eurasian wild boar in Mediterranean woodland habitats. Eur. J. Wildl. Res. 57, 749-757.

Barrios-Garcia, M.N., Ballari, S.A., 2012. Impact of wild boar (Sus scrofa) in its introduced and native range: a review. Biol. Invasions 14, 2283-2300.

Barton, K., 2009. MuMIn: Multi-Model Inference, R Package Version 0.12. 0. http: $/ /$ r-forge.r-project.org/projects/mumin/.

Bates, D., Mächler, M., Bolker, B., Walker, S., 2014. Fitting Linear Mixed-Effects Models Using Lme4, 51pp. 1406.5823.

Bengsen, A.J., Gentle, M.N., Mitchell, J.L., Pearson, H.E., Saunders, G.R., 2014. Impacts and management of wild pigs Sus scrofa in Australia. Mamm Rev. 44, 135-147.

Benhamou, S., 2011. Dynamic approach to space and habitat use based on biased random bridges. PLoS One 6, e14592.

Benhamou, S., Cornelis, D., 2010. Incorporating movement behavior and barriers to improve kernel home range space use estimates. J. Wildl. Manag. 74, 1353-1360.

Bevins, S.N., Pedersen, K., Lutman, M.W., Gidlewski, T., Deliberto, T.J., 2014. Consequences associated with the recent range expansion of nonnative feral swine. Bioscience 64, 291-299.

Bodenchuk, M., 2014. Method-specific costs of feral swine removal in a large metapopulation: the Texas experience. Proceedings of the 26th Vertebrate Pest Conference 269-271.

Brook, R.K., van Beest, F.M., 2014. Feral wild boar distribution and perceptions of risk on the central Canadian prairies. Wildl. Soc. Bull. 38, 486-494.

Brown, R.D., Cooper, S.M., 2006. In my opinion: the nutritional, ecological, and ethical arguments against baiting and feeding white-tailed deer. Wildl. Soc. Bull. 34, $519-524$.

Burnham, K.P., Anderson, D.R., 2002. Model Selection and Multimodel Inference: a Practical Information-Theoretic Approach, second ed. Springer Science \& Business Media, New York, NY, USA.

Calenge, C., 2006. The package "adehabitat" for the R software: a tool for the analysis of space and habitat use by animals. Ecol. Model. 197, 516-519.

Campbell, T.A., Lapidge, S.J., Long, D.B., 2006. Using baits to deliver pharmaceuticals to feral swine in southern Texas. Wildl. Soc. Bull. 34, 1184-1189.

Campbell, T.A., Long, D.B., Lavelle, M.J., Leland, B.R., Blankenship, T.L., VerCauteren, K. C., 2012. Impact of baiting on feral swine behavior in the presence of culling activities. Prev. Vet. Med. 104, 249-257.

Campbell, T.A., Long, D.B., Leland, B.R., 2010. Feral swine behavior relative to aerial gunning in southern Texas. J. Wildl. Manag. 74, 337-341.

Campbell, T.A., Long, D.B., Shriner, S.A., 2013. Wildlife contact rates at artificial feeding sites in Texas. Environ. Manag. 51, 1187-1193.

Choquenot, D., Kilgour, R.J., Lukins, B.S., 1993. An evaluation of feral pig trapping. Wildl. Res. 20, 15-21.

Corn, J.L., Jordan, T.R., 2017. Development of the national feral swine map, 1982-2016. Wildl. Soc. Bull. 41, 758-763.

Davis, A.J., Leland, B., Bodenchuk, M., VerCauteren, K.C., Pepin, K.M., 2017. Estimating population density for disease risk assessment: the importance of understanding the area of influence of traps using wild pigs as an example. Prevent. Veterinary. Med. 141, 33-37.

Davis, A.J., Leland, B., Bodenchuk, M., VerCauteren, K.C., Pepin, K.M., 2018. Costs and Effectiveness of Damage Management of an Overabundant Species (Sus scrofa) Using Aerial Gunning. Wildlife Research in press.

Delgado-Acevedo, J., DeYoung, R.W., Campbell, T.A., 2013. Effects of local-scale removals on feral swine populations in southern Texas. Int. J. Pest Manag. 59, $122-127$.

Dexter, N., McLeod, S.R., 2015. Modeling ecological traps for the control of feral pigs. Ecol. Evol. 5, 2036-2047.

Ditchkoff, S.S., Holtfreter, R.W., Williams, B.L., 2017. Effectiveness of a bounty program for reducing wild pig densities. Wildl. Soc. Bull. 41, 548-555.

Ditchkoff, S.S., Mayer, J., 2009. Wild pig food habits. In: Mayer, J.J., Brisbin, andI. L. (Eds.), Wild Pigs Biology, Damage, Control Techniques and Management Savannah River Nuclear Solutions. LLC, Savannah River National Laboratory, Aiken, South Carolina, USA.

Dunkley, L., Cattet, M., 2003. A comprehensive review of the ecological and human social effects of artificial feeding and baiting of wildlife. Canada. Cooperate. Wildlife. Health. Centre: Newslett. Pub. 21, 68.

Engeman, R., Massei, G., Sage, M., Gentle, M., 2013. Monitoring wild pig populations: a review of methods. Environ. Sci. Pollut. Control Ser. 20, 8077-8091. 
Fauchald, P., Tveraa, T., 2003. Using first-passage time in the analysis of area-restricted search and habitat selection. Ecology 84, 282-288.

Gamelon, M., Gaillard, J.M., Servanty, S., Gimenez, O., Toigo, C., Baubet, E., Klein, F., Lebreton, J.D., 2012. Making use of harvest information to examine alternative management scenarios: a body weight-structured model for wild boar. J. Appl. Ecol. 49, 833-841.

Henry, V., 1966. European wild hog hunting season recommendations based on reproductive data. Southeastern Association of Game and Fish Commissioners 20, 139-145.

Hone, J., Pedersen, H., 1980. Changes in a feral pig population after poisoning. In Clark, J.P., Marsh, andR. E. (Eds.), Proceedings of the 9th Vertebrate. Pest Conference University of California, Davis, USA, pp. 176-182.

Hudler, D.B., 2000. Modeling Paleolandscapes in Central Texas. Ph.D. Dissertation. University of Texas at Austin, USA.

Keiter, D.A., Mayer, J.J., Beasley, J.C., 2016. What is in a "common" name? A call for consistent terminology for nonnative Sus scrofa. Wildl. Soc. Bull. 40, 384-387.

Keuling, O., Stier, N., Roth, M., 2008. How does hunting influence activity and spatial usage in wild boar Sus scrofa L.? Eur. J. Wildl. Res. 54, 729.

Koos, W.M., Williams, J.C., Dixon, M.L., 1962. Soil Survey, Wilbarger County, Texas. US Department of Agriculture, Soil Conservation Service.

Lavelle, M.J., Snow, N.P., Fischer, J.W., Halseth, J.M., VanNatta, E.H., VerCauteren, K. C., 2017. Attractants for wild pigs: current use, availability, needs, and future potential. Eur. J. Wildl. Res. 63, 86.

Lavelle, M.J., Snow, N.P., Halseth, J.M., Kinsey, J.C., Foster, J.A., VerCauteren, K.C., 2018. Development and evaluation of a bait station for selectively dispensing bait to invasive wild pigs. Wildl. Soc. Bull. 42, 102-110.

Lavelle, M.J., Snow, N.P., Halseth, J.M., VanNatta, E.H., Sanders, H.N., VerCauteren, K. C., 2018. Evaluation of movement behaviors to inform toxic baiting strategies for invasive wild pigs (Sus scrofa). Pest Manag. Sci. 74, 2504-2510.

Mayer, J., Brisbin, I.L. (Eds.), 2009. Wild Pigs: Biology, Damage, Control Techniques an Management. Savannah River National Laboratory, Aiken, South Carolina, USA.

Mazerolle, M.J., 2017. Package 'AICcmodavg'. R Package. http://camoruco.ing.uc.edu. ve/cran/web/packages/AICcmodavg/AICcmodavg.pdf.

McRae, J.E., Schlichting, P.E., Snow, N.P., Davis, A.J., VerCauteren, K.C., Kilgo, J.C., Keiter, D.A., Beasley, J.C., 2019. Factors Affecting Bait Site Visitation: Area of Influence of Baits the Wildlife Society Bulletin:in Revision.

Muir, T., McEwen, G., 2007. Methods and strategies for managing feral hog damage in grain production areas in central Texas. In: Witmer, G.W., Pitt, W.C., Fagerstone, andK. A. (Eds.), Managing Vertebrate Invasive Species: Proceedings of an International Symposium. USDA/APHIS/WS, National Wildlife Research Center, Fort Collins, CO, pp. 445-450.

Pebesma, E., Bivand, R.S., 2005. Classes and methods for spatial data: the sp package. R. News 5, 9-13.

Poché, R.M., Poché, D., Franckowiak, G., Somers, D.J., Briley, L.N., Tseveenjav, B., Polyakova, L., 2018. Field evaluation of low-dose warfarin baits to control wild pigs (Sus scrofa) in North Texas. PLoS One 13, e0206070.

Rosa, C.A.D., Wallau, M.O., Pedrosa, F., 2018. Hunting as the main technique used to control wild pigs in Brazil. Wildl. Soc. Bull. 42, 111-118.
Rudolph, B.A., Riley, S.J., Hickling, G.J., Frawley, B.J., Garner, M.S., Winterstein, S.R., 2006. Regulating hunter baiting for white-tailed deer in Michigan: biological and social considerations. Wildl. Soc. Bull. 34, 314-321.

Saunders, G., Kay, B., Nicol, H., 1993. Factors affecting bait uptake and trapping success for feral pigs (Sus scrofa) in Kosciusko National Park. Wildl. Res. 20, 653-665.

Schley, L., Roper, T.J., 2003. Diet of wild boar Sus scrofa in Western Europe, with particular reference to consumption of agricultural crops. Mamm Rev. 33, 43-56.

Snow, N.P., Halseth, J.M., Lavelle, M.J., Hanson, T.E., Blass, C.R., Foster, J.A., Humphrys, S.T., Staples, L.D., Hewitt, D.G., VerCauteren, K.C., 2016. Bait preference of free-ranging feral swine for delivery of a novel toxicant. PLoS One 11, e0146712.

Snow, N.P., Jarzyna, M.A., VerCauteren, K.C., 2017. Interpreting and predicting the spread of invasive wild pigs. J. Appl. Ecol. 54, 2022-2032.

Snow, N.P., Lavelle, M.J., Halseth, J.M., Blass, C.R., Foster, J.A., Vercauteren, K.C., 2017. Strength testing of raccoons and invasive wild pigs for a species-specific bait station. Wildl. Soc. Bull. 41, 264-270.

Snow, N.P., Lavelle, M.J., Halseth, J.M., Glow, M.P., VanNatta, E.H., Davis, A.J., Pepin, K.M., Tabor, R.T., Leland, B.R., Staples, L.D., VerCauteren, K.C., 2018. Exposure of a Population of Invasive Wild Pigs to Simulated Toxic Bait Containing Biomarker: Implications for Population Reduction. Pest Management Science in press.

Sorensen, A., van Beest, F.M., Brook, R.K., 2014. Impacts of wildlife baiting and supplemental feeding on infectious disease transmission risk: a synthesis of knowledge. Prev. Vet. Med. 113, 356-363.

Spencer, P.B., Lapidge, S.J., Hampton, J.O., Pluske, J.R., 2005. The sociogenetic structure of a controlled feral pig population. Wildl. Res. 32, 297-304.

Steen, D., 2006. The benefits of aerial hunting for feral hog management in southeast Texas pasture and rangelands. Proceedings of the 22nd Vetebrate Pest Conference 361-363.

Sweitzer, R.A., Ghneim, G.S., Gardner, I.A., Vuren, D.V., Gonzales, B.J., Boyce, W.M., 1997. Immobilization and physiological parameters associated with chemical restraint of wild pigs with Telazol $®$ and xylazine hydrochloride. J. Wildl. Dis. 33, 198-205.

The Wildlife Society, 2007. Final TWS position statement, baiting and supplemental feeding of game wildlife species. http://wildlife.org/wp-content/uploads/2014/05/ PS_BaitingandSupplementalFeeding.pdf. (Accessed 19 November 2018).

The effectiveness of trapping in reducing pig abundance in the wet tropics of north Queensland. In: Vernes, K., Johnson, C., Mitchell, J. (Eds.), 2001. Proceedings of a Feral Pig Workshop. James Cook University, Cairns, March. Research Report No. 13. Cooperative Research Centre for Tropical Rainforest Ecology and Management, Cairns, Australia.

Williams, B.L., Holtfreter, R.W., Ditchkoff, S.S., Grand, J.B., 2011. Efficiency of timelapse intervals and simple baits for camera surveys of wild pigs. J. Wildl. Manag. 75, 655-659.

Williams, B.L., Holtfreter, R.W., Ditchkoff, S.S., Grand, J.B., 2011. Trap style influences wild pig behavior and trapping success. J. Wildl. Manag. 75, 432-436.

Wills, F.H., 2006. Historic vegetation of camp Bullis and camp stanley, southeastern Edwards Plateau, Texas. Tex. J. Sci. 58, 219-230.

Zhang, Y.W., 2013. Cplm: Compound Poisson Linear Models. A Vignette for R Package Cplm, p. 621. Available at: http://cran.r-project.org/web/packages/. 